\title{
Effect of Cutting Speed in Turning Process using Finite Element Modeling
}

\author{
M. Sivaramakrishnaiah \\ Assistant Professor of Mechanical Engineering \\ Sri Venkateswara College of Engineering \& Technology, \\ (Autonomous),Chittoor. A.P, India. \\ Dr. P. Nanda Kumar \\ Professor of Mechanical Engineering, \\ NBKR institute of Science and Technology, \\ Vidyanagar, Nellore AP, India.
}

\begin{abstract}
In this research work present a Finite element modelling as 3D effects to machining of cutting speed in tuning process. The Inconel 600 wokpiece and tungsten carbide tool material selected. In this machining processes, the cutting speeds were selected some parameters, depth of cut, feed were selected as constant. In Abaqus software was used for simulated the turning processes. In this work effects on the temperature, cutting forces, stresses of cutting speed, feed, depth of cut. Result, the temperature on the cutting tool increases with increasing cutting speed. Variations in shear stress occurring on the rake face of the tool.
\end{abstract}

Keywords: ALE,FEM, crater wear, cutting speed, feed.

\section{INTRODUCTION}

Machining is one of the most widely used production technique in industry for converting preformed blocks of metal into desired shapes with surface quality and dimensional accuracy. These shaping operations are done in forms of metal chips. The turning process used widely in industry, has countless applications. Traditionally, the process is used to reduce the diameter of cylindrical work piece, or to change a work piece of non-circular crosssection. This is done by rotating the work piece about of the machine's axis of spindle and removing the material with the cutting tool, fed in the perpendicular direction. For the past fifty years, metal cutting researchers for simulation purposes have developed many modeling techniques including analytical techniques, slip-line solutions, empirical approaches and finite element techniques. In recent years, the finite element analysis has particularly become the main tool for simulating metal cutting processes.

Finite element analysis widely used for calculating the stress, strain, strain-rate distributions in the primary, secondary and tertiary sub-cutting zones. In consequence, the tool, chip and work piece, as well as cutting forces, elasto-plastic deformation (shear angles and chip thickness), chip formation and possibly its breaking can be determined faster than using costly and time consuming experiments. In this work, FEA based models are developed that are able to predict the effect of various process variables on the performance measures such as cutting forces, stresses and strains.

\section{LITERATURE REVIEW}

In this paper,2D finite element modelling of orthogonal metal cutting operation are presented with the use of Abaqus.Jaharah et al[1] proposed that the application of Finite element method in simulating the effect of cutting tool geometries on the effective stress and temperature increased in turning ALSI 1045. Bareggi et al [2] proposed that a supersonic nozzle has been used to generate a high velocity air jet to provide cooling at the toolchip interface during metal cutting. Recently, the application of finite element method (FEM) in metal cutting process was a great help for researchers in study of metal cutting and chip formation. D. D.Umbrello [3] proposed that, Numerical simulation is usefull to study various phenomenon such as chip segmentation, cutting force, wear rate of cutting tool. Heat is transferred across boundaries by conduction, convection and radiation because of the temperature gradient, and air present at ambient temperature [4]. Heat transfer inside the chip and workpiece, the tool and tool-holder is by conduction. Heat transfer between coolant/air and the chip/tool/workpiece is by convection. Radiation is rarely investigated in traditional machining operations. Patrascu and Carutasu [5] proposed that FEM model for 3D simulation of turning process. Zhou et al. [6] presented a study of the effect of chamfer angle on tool wear of PCBN cutting tool. Outeiro et al (2004) [7] developed a 3D dynamic temperature field control models that calculates the temperature of heat sources in the 
light of tool temperature distribution information. The materials used for machining includes Ti-6Al-V4 and AISI 1008, with varying LN2 coolant jet configurations and then analyzed using finite element technique. Number of researchers has relied on the Lagrangian formulation[ 8], which allows the chip to be modelled from incipient to steady state where as some of the studies also used Eulerian formulation,ALE.

Table 1.Material Properties of Inconel 600 workpiece and cutting parameters used in the simulation.

\begin{tabular}{|c|c|}
\hline Cutting parameters & Values \\
\hline Worpiece material & Inconel 600 \\
\hline Tool material & WC(Tungsten Carbide) \\
\hline Inset Type & CNMA 432 \\
\hline Cutting tool tip radius & 0.8 \\
\hline Rake angle & 0 \\
\hline Clearance angle & $65,85,95$ \\
\hline Cutting speed $(\mathrm{m} / \mathrm{min})$ & 0.3 \\
\hline Depth of cut $(\mathrm{mm})$ & 0.06 \\
\hline Feed rate $(\mathrm{mm} / \mathrm{rev})$ & $25^{\circ}$ \\
\hline Temperature & 25 \\
\hline Cutting length & $20 \mathrm{~mm}$ \\
\hline Heat Transfer coefficient $\left(\mathrm{W} / \mathrm{m}^{\circ} \mathrm{K}\right)$ & 0.6 \\
\hline Yong Modulus $(\mathrm{Gpa})$ & 200 \\
\hline Poisson ratio & 0.324 \\
\hline Thermal Conductivity $\left(\mathrm{W} / \mathrm{m}^{\circ} \mathrm{C}\right)$ & 47.7 \\
\hline Heat Capacity $\left(\mathrm{N} / \mathrm{mm}^{20} \mathrm{C}\right)$ & 432.6 \\
\hline Shear factor & 0.8 \\
\hline
\end{tabular}

\section{FINITE ELEMENT MODELING}

3.1 Modeling: A Finite Element model, implemented in Abaqus, as shown in fig where it is possible to see the workpiece with the chip developing and tool. The tool is deformed and workpiece is fixed. Tool object meshed with more than 10000 elements, is oriented according to cutting angle set in simulation test and reported in table and it moves along a linear directions. And mean while workpiece and tool material properties defined in Table 1.The workpiece, considered as a plastic object meshed with more than 5000 elements, is fully constrained on the lower and lateral sides so it cannot move..On the same face thermal boundary conditions are set so to simulate the heat diffusion. Thermal exchange between tool and chip is regulated by heat diffusion relationship whose characteristic parameters are reported in table The friction wad modelled considering a shear factor equal to 0.8 .

\subsection{MESH GENERATION \& BOUNDARY CONDITIONS:}

Tool mesh and geometry For computational efficiency a small section of the workpiece (15mm x $5 \mathrm{~mm})$ was modeled. The wokpiece shape is constructed by the Abaqus software. A minimum element size of $0.25 \mathrm{~mm}$ was specified. The remeshing system uses the minimum element size in the interface area and substantially larger elements in the surrounding area. The total number of elements was approximately 16000.An unstructured mesh was also used on the cutting inset for thermal calculations. The mesh generation starts by creating elements along work piece boundary and cutting tool. The tool mesh with min element size of $0.25 \mathrm{~mm}$ is considered and is shown in Fig. 1 The meshing elements and boundary conditions used at the contact surface between the cutting tool edge and work piece. Enter the number of simulations as 200 steps and collect the forces data after completion of simulations on Abaqus in the post processor group. 


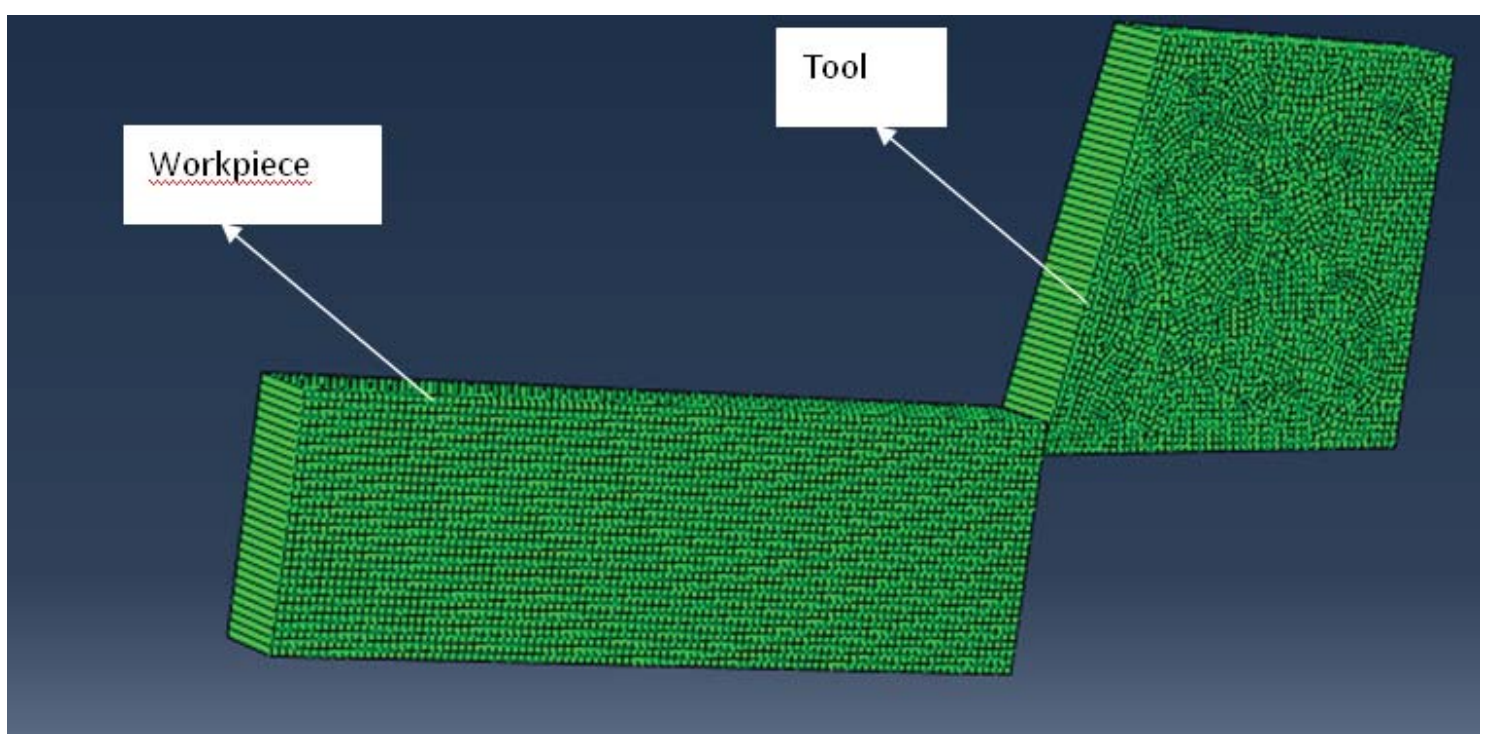

Fig 1.3D Mesh Generation of tool and wokpiece

\section{RESULTS}

In this simulation Cutting speeds varies temperature distribution which occurred on the cutting tool has been determined as Abaqus software. With increasing of cutting speed has been a reduce in the cutting forces. This state is about with high temperature occurred in the tool chip interface in the high cutting speeds. Another factors affecting the cutting performance of the cutting tool. To determine stresses occurred on the cutting tool had added a new operation. As a result of the analysis, it can be seen that temperature in the cutting region increases with increasing of the temperature will cause thermal softening in the workpiece. Thus chip will separate easier from the workpiece. This reduction in the cutting forces will also cause a reducing in the stress occurred on the cutting tool as shown in Fig 2,3. It can be seen that temperature increases with increasing of cutting speed. In Fig 4 temperature different values seen occurred five different points on the rake face of the cutting tool during $0.005 \mathrm{sec}$ cutting process. During these regions are $\mathrm{A}_{1}, \mathrm{~A}_{2}, \mathrm{~A}_{3}, \mathrm{~A}_{4}, \mathrm{~A}_{5}$ compare to five region of points 4 th region maximum temperature, there is possibility of a crater wear.



Fig 2. Stress and Temperature distribution of workpiece and tool 
Table 2.Different parameters of Temperatures, Forces and Stresses

\begin{tabular}{|c|c|c|c|c|c|c|}
\hline S.No. & $\begin{array}{l}\text { Cutting } \\
\text { speed } \\
(\mathrm{m} / \mathrm{min})\end{array}$ & $\begin{array}{l}\text { Feed } \\
(\mathrm{mm} / \mathrm{rev})\end{array}$ & $\begin{array}{l}\text { Depth of cut } \\
\text { (mm) }\end{array}$ & $\begin{array}{l}\text { Temperature } \\
{ }^{\circ} \mathrm{C}\end{array}$ & Stress (Mpa) & $\begin{array}{l}\text { Resultant Force } \\
\text { (N) }\end{array}$ \\
\hline 1 & 65 & \multirow{5}{*}{0.08} & \multirow{5}{*}{0.3} & 356 & 5002 & 269.45 \\
\hline 2 & 85 & & & 421 & 3520 & 237.32 \\
\hline 3 & 95 & & & 501 & 3001 & 123.18 \\
\hline 4 & 110 & & & 462 & 2502 & 113 \\
\hline 5 & 125 & & & 452 & 2800 & 106 \\
\hline
\end{tabular}

Stress Mpa

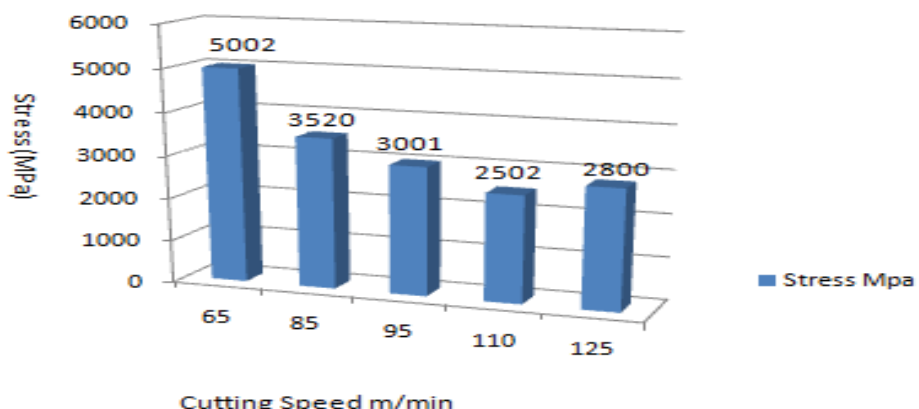

Fig 3.Variation of Cutting force with cutting speed

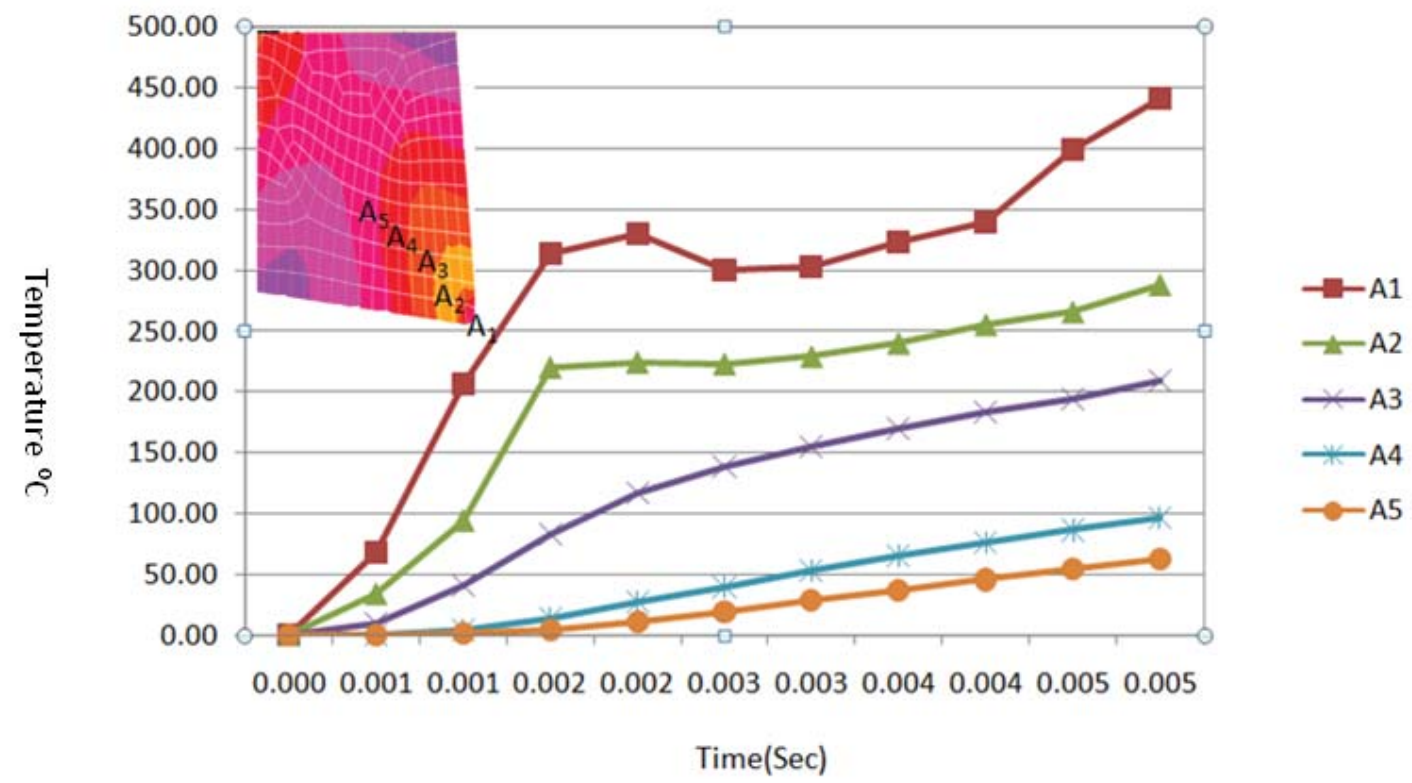

Fig 4. Temperature values in different positions

\section{CONCLUSIONS}

1.Temperature on the tool increases with increases with increasing cutting speed.10 different points were selected on the rake face of the cutting tool during $0.001 \mathrm{sec}$ cutting process. The highest temperature between these points was occurred in the region A3 point may be in this region, there is possibility of the crater wear.

2.It seen that a decreasing in the cutting forces with increasing cutting speed.

3.Decresing cutting forces will also reason a reducing in the stresses occurring on the cutting tool. 


\section{REFERENCES}

[1] A.G.Jaharah, S.W.Wahid, C.H.Che, M.Z.Nuawi, N.R.Mohd," The Effect of Uncoated carbide Tool Geometries in Turning ALSI 1045 using Finite element analysis", European Journal of Scientific Research,2,009,271-277.

[2] Bareggi, A.; Donnell, O.; Torrance, A.: Modelling Thermal Effects in Machining By Finite Element Methods, Processing of the 24 th International Manufacturing Conference, 29th-31st August, Waterford 1.1, 2007, 263-272.

[3] D. D.Umbrello, L.Filice, S.Rizzuti, F.Micari, L. Settineri, 2007. On the effectiveness of Finite Element simulation of orthogonal cutting with particular reference to temperature prediction. Journal of Materials Processing Technology 189 (2007) 284-291.

[4] Ostafiev V., Kharkevich A.,Weinert K.,Ostafiev S., "Tool Heat Transfer in Orthogonal Metal Cutting", Journal of Manufacturing Science and Engineering, vol. 121(1999),pp. 541-549.

[5] G. Patrascu, G. Carutasu, "Using Virtual Manufacturing Simulation in 3D Cutting Forces Prediction", Fascicle of Management and Technological Engineering, Volume VI (XVI), 2007, 1423-1426.

[6] J. M. Zhou, H. Walter, M. Andersson, J. E. Stahl,: "Effect of Chamfer Angle on Wear of PCBN Cutting Tool", International Journal of Machine Tools \& Manufacture, 43, 2003, 301305.

[7] Silva, M.B. and Wallbank, J. (1999). Cutting Temperature: Prediction and Measurement Methods- A Review. Journal of Materials Processing Technology, 88:195-202.

[8] Stenkowski,J.S., and Carroll,J.M.,1996," Finite element models of orthogonal cutting with application to single point dimong turning',International Journal of Mechanical Science,30,899-553. 